\title{
Ni-Sm (Nickel-Samarium)
}

\section{H. Okamoto}

The Ni-Sm phase diagram in [Massalski2] was redrawn from [1991Pan], which is primarily based on the experimental phase boundary data of [1983Pan]. [1998Su] calculated the $\mathrm{Ni}$-Sm phase diagram using the same experimental data of [1983Pan] and enthalpy of formation data available for $\mathrm{Ni}_{5} \mathrm{Sm}, \mathrm{Ni}_{7} \mathrm{Sm}_{2}, \mathrm{Ni}_{3} \mathrm{Sm}$, and $\mathrm{Ni}_{2} \mathrm{Sm}$. The result is shown in Fig. 1. The strong asymmetry of the NiSm liquidus shown in [1991Pan], which is unlikely according to [1991Oka], was eliminated in this phase diagram.

\section{References}

1983Pan: Y.Y. Pan and C.S. Cheng: Acta Phys. Sinica, 1983, vol. 32 (1), pp. $92-95$ (in Chinese).

1991Pan: Y.Y. Pan and P. Nash: Phase Diagrams of Binary Nickel Alloys, P. Nash, ed., ASM International, Materials Park, OH, 1991, pp. 307-10.

1991Oka: H. Okamoto and T.B. Massalski: J. Phase Equilibria, 1991, vol. 12 (2), pp. 148-68.

1998Su: X. Su, W. Zhang, and Z. Du: J. Alloys Compounds, 1998, vol. 278 , pp. 182-84.

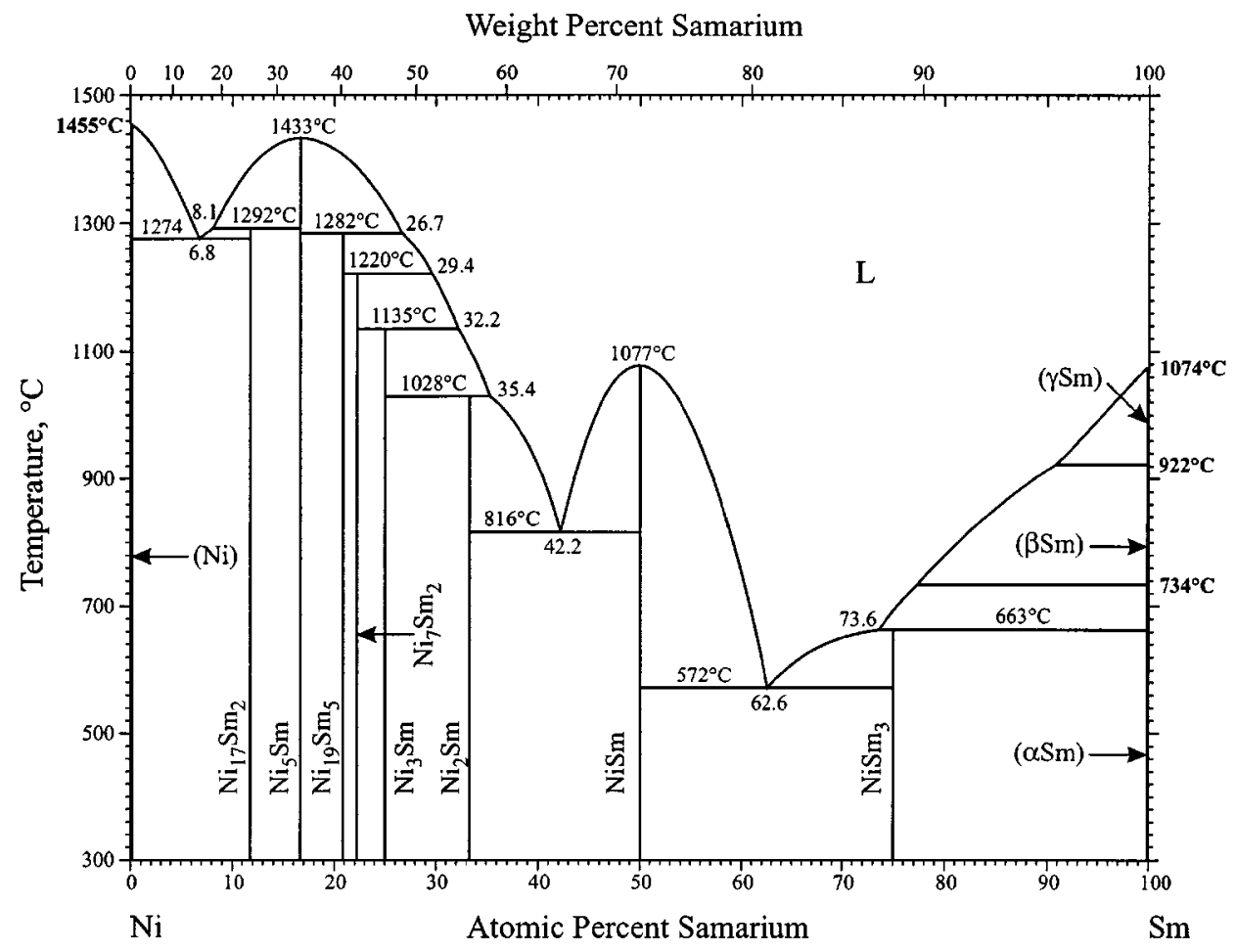

Fig. 1 Ni-Sm phase diagram 